\title{
The Race to a Tobacco Endgame
}

\section{Ruth E Malone}

During the past month alone, I have had an opportunity to participate in four different meetings-in Utah, Sweden, Canada and the USA-where ideas about how to achieve an 'endgame' for the tobacco epidemic were being discussed. Other previous meetings-in India, Finland and the UK-have been held over the last few years, and I know of several other such discussions. Even before the US Surgeon General's 50th Anniversary report on the health consequences of smoking ${ }^{1}$ called explicitly for achieving a tobacco endgame and suggested a combination of policy strategies to do so, other countries such as Ireland, New Zealand, Finland and Scotland were having conversations that led them to set hard target dates by which they intend to reduce tobacco use and/or smoking prevalence to $<5 \%$.

Modelling studies suggest that current measures, even if they are greatly accelerated in countries that are tobacco control leaders, will not achieve these goals within the first half of this century. ${ }^{1}$ As the target dates move closer, will political leaders seize the opportunity to enact the bolder policy innovations that must be undertaken? Or, will they allow caution and inertia to shape another century of public health catastrophe?

The endgame requires consciously designing interventions to change permanently the structural, political and social dynamics that sustain the epidemic, in order to end it by a specific time. ${ }^{2}$ Thus, an endgame vision goes beyond 'business as usual' and calls for further policy innovations. No one knows how to do it yet, but the endgame conversation ${ }^{3-6}$ has become mainstream, and the first places that manage to achieve it will herald the beginning of the end of more than a century of industrially produced carnage. Which places will be first to cross the finish line?

Several factors will likely be decisive.

The first of these is whether the public health community can achieve some rough unity as to the goal and strategies to be employed. We do not have to agree on everything, and some places will do things

Correspondence to Professor Ruth E Malone, Department of Social and Behavioral Sciences, School of Nursing, University of California, San Francisco, CA 94118, USA; ruth.malone@ucsf.edu differently than others, but within any locale, some consensus will be needed or we risk confusing the public and giving policymakers more excuses not to act. There is no doubt that the tobacco industry is eager to exploit and/or create such divisions, ${ }^{7}$ so compromises will be needed. The controversy over e-cigarettes, for example, has created multiple lines of division among public health proponents. This disunity does not serve well the advancement of new policy measures to end the epidemic. ${ }^{8}$ Yet, e-cigarettes and the burgeoning list of other non-combustible tobacco and nicotine products could represent potential leverage for accomplishing what once seemed unthinkable: phasing out combustible cigarettes, the single most deadly consumer product ever marketed. Yes, these other products may cause harm. Yes, there may be unintended and unanticipated negative consequences. But we do not require a single additional study to know with absolute certainty that the continued sale and use of cigarettes will reliably deliver more disease, death and suffering than any other product. And we do know that for at least some people who smoke, the use of these alternative tobacco and nicotine products is acceptable as a substitute or a transition to quitting. Let's keep our eyes on the prize.

The second decisive factor is whether the ground has been sufficiently prepared in getting the public to believe in and support ending the tobacco epidemic. The incongruence of telling the public how bad cigarettes are, while simultaneously continuing to allow their widespread retail sale, contributes to confusion at best and cynicism at worst. In this regard, multiple studies from various countries suggest that the public-including smokers - may be further along the road to an endgame than we public health proponents have allowed ourselves to go. In Canada, for example, data from Wave 9 and preliminary analyses of Wave 10 of the ITC Survey, a nationally representative cohort study, show that more than half of smokers would support a complete ban on cigarettes within 10 years, if the government provided assistance to quit. $^{9}$ These findings are consistent with several studies conducted in other countries, as well as internal data from tobacco company Philip Morris's own public opinion surveys, which found that in the
USA in 2004, $68 \%$ of those surveyed wished there was some way to get rid of cigarettes. $^{10-12}$ However, such findings have never been used to develop effective campaign messaging to build a constituency for endgame measures.

A third element is whether policymakers in the location are courageous enough to tackle something new and politically risky, about which they will incur attacks from tobacco companies and their allies. Big Tobacco will raise every conceivable argument, arguing that protecting the public from these unreasonably dangerous and defective products infringes on rights, will create vast black markets, and will ruin economies. But governments have an obligation to act to protect public health, tobacco companies themselves have been implicated in black market trading, and to argue that we must keep killing people in order to sustain our economy seems to put the entire social enterprise in question. In addition, the places now closest to achieving a tobacco endgame are those where prevalence has dropped to historical lows, suggesting that the transition to new economic and business models is inevitable: policymakers should be anticipating and preparing for a different kind of economy.

Finally, achieving a tobacco endgame will reflect how well public health proponents work alongside and with the communities that are now most affected by the tobacco epidemic. 'Nothing about us without us' is an important principle as smoking and tobacco use become more concentrated among certain population groups, each of which has different resources, needs and priorities. The tobacco industry's targeting and exploitation is one part of how these disparities in tobacco use came to be, but the whole story is much more complex, especially for indigenous peoples. Now Big Tobacco hides behind these groups, claiming, for example, that tax increases hurt the poor-despite evidence that such increases actually benefit poor people more (because they quit in greater numbers) than wealthier groups. ${ }^{13}$ But those alliances are beginning to fray. For example, activists in the US African-American community, concerned with the consequences of high menthol cigarette use, are providing aggressive leadership on efforts to pressure government to get menthol out of tobacco products. ${ }^{14}$ New Zealand Maori leaders' report in 2010 led to establishment of that country's Smokefree 2025 goal. $^{15}$

While for many countries, combustible tobacco products are the biggest issue to be addressed, in others like India, dangerous oral tobacco products proliferate. Some countries already have robust 
regulatory infrastructures that are trusted by the public; others are only beginning to build the capacity that would allow more radical measures such as limiting sales outlets for cigarettes or setting a timetable for a phaseout. This is why 'there is no single endgame', as Arnott ${ }^{16}$ pointed out several years ago. But even tobacco companies are beginning to realise that the endgame is in sight.

I recently received in the mail a heavy envelope from overseas, containing a 'Global Compact Report' from Philip Morris International, along with a personalised letter encouraging me to review it and engage in dialogue. One line jumped out at the end of the first paragraph, which focused largely on spin about the company's latest reinvention of itself as a responsible, transparent seller of death and disease: a reference to 'acknowledging and addressing the social harms caused by our products, including the phase out of combustible cigarettes'. This oddly written sentence would be cause for genuine excitement if the report actually said anything specific about phasing out cigarettes, but it did not appear to do that. Nowhere could I find any plan or timetable for such a phaseout, despite the company's touting of new 'heat-not-burn' products and reference to leading an effort to 'replace' cigarettes with them. Elsewhere, such products are also reassuringly reported as not 'cannibalising' existing cigarette brands in test markets, ${ }^{17}$ suggesting they are not really seen as substitutes for them any time in the near future. Meanwhile, the industry keeps marketing the same old deadly stuff all over the world. So, we simply cannot count on the tobacco companies to make the endgame happen.

They are getting ready for us to tell them they have to stop. But we have to make them do it. Let's tell them when this epidemic has to end.

Which country will go first?

Competing interests None declared.

Provenance and peer review Not commissioned; internally peer reviewed.

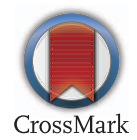

To cite Malone RE. Tob Control 2016;25:607-608.

Accepted 5 October 2016

Tob Control 2016;25:607-608.

doi:10.1136/tobaccocontrol-2016-053466

\section{REFERENCES}

1 US Department of Health and Human Services. The health consequences of smoking: 50 years of progress: a report of the Surgeon General. Atlanta, GA: US Department of Health and Human Services, Centers for Disease Control and Prevention, National Center for Chronic Disease Prevention and Health Promotion, Office on Smoking and Health, 2014.

2 Malone RE, McDaniel PA, Smith EA. Tobacco control endgames: global initiatives and implications for the UK. Cancer Research UK, 2014. http:// wwwcancerresearchukorg/sites/default/files/policy_ july2014_fullendgame_reportpdf

3 Malone RE. Imagining things otherwise: new endgame ideas for tobacco control. Tob Control 2010;19:349-50.

4 Smith EA. Questions for a tobacco-free future. Tob Control 2013;22(Supp1 1):i1-2.
5 Warner KE. An endgame for tobacco? Tob Control 2013;22(Supp1 1):i3-5.

6 McDaniel PA, Smith EA, Malone RE. The tobacco endgame: a qualitative review and synthesis. Tob Control 2016;25:594-604.

7 McDaniel PA, Smith EA, Malone RE. Philip Morris's Project Sunrise: weakening tobacco control by working with it. Tob Control 2006;15:215-23.

8 Gartner C, Malone RE. Duelling letters: which one would you sign? Tob Control 2014;25:369-70.

9 Chung-Hall J, Craig L, Driezen P, et al. Canadian smokers' support for tobacco endgame strategies: findings from the ITC Canada Survey. Ontario, Canada: ITC Project University of Waterloo, 2016.

10 Edwards R, Wilson N, Peace J, et al. Support for a tobacco endgame and increased regulation of the tobacco industry among New Zealand smokers: results from a National Survey. Tob Control 2013;22:e86-93.

11 Wang MP, Wang X, Lam TH, et al. The tobacco endgame in Hong Kong: public support for a total ban on tobacco sales. Tob Control 2015;24: 162-7.

12 Altria [Parrish S]. Corporate affairs societal alignment/regulation update. 2004. https:// wwwindustrydocumentslibraryucsfedu/tobacco/docs/ znyv0024

13 Furman J. Six lessons from the US experience with tobacco taxes. World Bank Conference paper: winning the tax wars: global solutions for developing countries 2016. https://www.whitehouse.gov/sites/default/files/ page/files/20160524_cea_tobacco_tax_speech.pdf

14 Tavernise S. Black health experts renew fight against menthol cigarettes. New York Times. 13 September 2016.

15 Maori Affairs Committee. Inquiry into the tobacco industry in Aotearoa and the consequences of tobacco use for Maori. 49th Parliament, New Zealand. 2010. https://www.parliament.nz/ resource/en-NZ/49DBSCH_SCR4900_1/ 2fc4d36b0fbdfed73f3b4694e084a5935cf967bb

16 Arnott D. There's no single endgame. Tob Control 2013;22(Suppl 1):i38-i9.

17 Caplinger D. Philip Morris International, Inc's best move so far this year. The Motley Fool. 2016. http:// wwwfoolcom/investing/2016/08/26/philip-morrisinternational-incs-best-move-in-2016aspx 